\title{
To include or not include: renal dialysis policy in the era of universal health coverage
}

\author{
Expensive treatments such as renal dialysis are a challenge for countries aiming for universal \\ coverage. Yot Teerawattananon and colleagues set out a systematic approach to ensuring it is \\ affordable
}

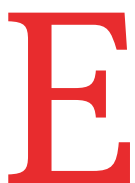

nd stage renal disease (ESRD) is a fatal condition that affects 10 million people annually. Although effective treatment exists, coverage remains low. In 2010 , only $27 \%$ of those in need of renal replacement therapy globally actually received it, with the proportion being between $2 \%$ and $5 \%$ in low and lower middle income countries. ${ }^{1}$ The rise in the ageing population coupled with increasing prevalence of diabetes and hypertension and other non-communicable diseases in low and middle income countries is expected to exacerbate the situation. In addition to investing in preventive interventions, countries will need to determine how best to provide expensive treatment. This is particularly challenging within the context of implementing universal health coverage (UHC). ${ }^{2}$ Policy makers need to ensure that their UHC programmes are ethical and make best use of resources.

We examine the challenges of implementing universal access to renal replacement therapy and offer a guide to

\section{SUMMARY POINTS}

- End stage renal disease (ESRD) is a life threatening condition that results in most patients requiring a lifetime of high cost renal dialysis

- Governments have grappled with the political, economic, and ethical challenges of providing treatment with their available budgets

- This tension is more prominent in resource limited countries that have committed to universal health coverage

- A systematic approach to inform universal renal dialysis policy can provide feasible, affordable, and scalable care

- Providing peritoneal dialysis as first line of treatment is the most feasible option for low and middle income countries help policy makers navigate the decision making process.

The problem: limited access to expensive care Dialysis costs are unaffordable for most people in low and middle income countries. A systematic review suggests that the annual direct cost of dialysis for one patient equals the average income of three people in an upper middle income country. ${ }^{3}$ The situation is worse in lower middle income countries, where six people's income would be needed to cover the cost of a year's dialysis for one patient; in a least developed country, the cost is equivalent to the average income of 12 people. ${ }^{3}$ These cost estimates explain why ESRD is a leading cause of catastrophic health expenditure and impoverishment worldwide.

ERSD can be treated with kidney transplantation or renal dialysis. ${ }^{4}$ Renal transplantation is the only definitive treatment, but access is limited because of low levels of organ donation or lack of infrastructure to support transplantation. The high upfront cost associated with renal transplantation can be a barrier for extending coverage to all patients, particularly in low and middle income countriess. ${ }^{5}$ Renal dialysis is therefore the most viable option for patients around the world. There are two options available for renal dialysis, haemodialysis and peritoneal dialysis, and health outcomes are similar for both. ${ }^{6}$ Haemodialysis is used most often but incurs high costs and is largely provided in centres in large cities; peritoneal dialysis is generally more cost effective and scalable as it is mainly carried out at home and has lower infrastructural requirements. ${ }^{\top}$

\section{Potential solutions}

Economic growth in South East Asia has resulted in improved living conditions and longer life expectancy for its population. ${ }^{89}$ Indonesia, the Philippines, and Thailand have all included renal dialysis in their UHC programmes but implemented it in different ways. The challenge of providing universal renal dialysis is particularly acute given resource constraints in the three settings, as income per capita ranges from $\$ 2900$ (£2200; €2600) to \$6600.9

Thailand did not include renal dialysis in its benefits package when the UHC programme was initiated in 2002 as it would have bankrupted the programme before it had even begun. Under pressure from civil society and professional groups, the Thai government commissioned studies to understand the situation for ESRD in the country and explored possible solutions to support households incurring debilitating costs to treat this disease. Researchers from the Thai Ministry of Public Health conducted a study that informed implementation of a cost effective policy for universal coverage. The policy dictated starting with peritoneal dialysis as opposed to free choice or haemodialysis first. ${ }^{4}$ This intervention was supplemented with other policies to incentivise healthcare providers to offer peritoneal dialysis, such as training nurses to administer peritoneal dialysis to patients, developing an extensive delivery system to provide the dialysis solution directly to patients' homes, and charges to discourage patients with ESRD who are medically fit for peritoneal dialysis from opting for haemodialysis. ${ }^{10}$ Even though Thailand had mainly used haemodialysis, it has been able to move to a system dominated by peritoneal dialysis in the 10 years since renal dialysis was added to the UHC benefits package. ${ }^{11}$

Indonesia and the Philippines both included ESRD in their benefits packages at the start of their UHC programmes, although without any policy assessment of the financial implications. Patients in these two countries can choose any dialysis option free of charge, but doctors commonly advise them to start with in-centre haemodialysis. In Indonesia, renal dialysis is fully covered by the Jaminan Kesehatan Nasional (JKN), which is one of the largest single payer health insurance schemes, covering 203 million people in 2018. ${ }^{12}$ The Philippines' scheme provides 
only partial coverage of haemodialysis, covering 90 of the 156 sessions normally required each year with the expectation that the remaining sessions would be paid for by patients. A recent study found that most patients have not been able to bear the cost of the remaining sessions. Consequently, patients have been forced to take a suboptimal number of haemodialysis sessions, lowering their quality of life and shortening their life expectancy by around eight years compared with dialysis patients in Indonesia and Thailand. ${ }^{13}$

Although dialysis was provided under Indonesia's UHC scheme, treatment remains elusive for a large proportion of the population. A study estimated that only $13 \%$ of ESRD patients had access to renal dialysis services in Indonesia because only 10 of the 6000 inhabited islands in Indonesia have a haemodialysis centre. ${ }^{14}$ There are even fewer peritoneal dialysis centres on these islands. The coverage of renal dialysis is also low in the Philippines $(22 \%),{ }^{15}$ whereas Thailand manages full coverage. ${ }^{16}$

In all three countries, renal dialysis was among the highest claim items in their national UHC programmes. The amount spent on renal replacement therapy, as a percentage of the total UHC budget, was $4.16 \%$ of $\$ 1.3 \mathrm{bn}$ in Indonesia, $7.7 \%$ of $\$ 1.9 \mathrm{bn}$ in the Philippines, and 5.1\% of $\$ 5.2 \mathrm{bn}$ in Thailand. This is a high expenditure on one disease since dialysis patients constitute only a small proportion of the UHC beneficiaries $(0.03 \%$ (63 818 patients) in Indonesia, 0.06\% (61763) in the Philippines, and $0.11 \%$ (53 234) in Thailand). ${ }^{16-18}$

\section{Policy choices for low and middle income countries}

Inclusion of renal dialysis in UHC benefits packages poses a challenge to many countries and requires both political and financial commitment. Many countries are seeking to implement universal dialysis, including Pakistan, Nigeria, Samoa, and India, which has announced it is setting up dialysis centres in around 700 districts and offering free haemodialysis to people below the poverty line. ${ }^{19-21}$

Based on our experience supporting the government implementation of renal dialysis policies in Indonesia, the Philippines and Thailand, we set out the policy choices for countries, particularly low and middle income, that are trying to provide universal renal replacement therapy to their citizens. Policy makers can use the questions below to drive the discourse on renal replacement therapy under UHC and to weigh the advantages and limitations of each policy option and build consensus among stakeholders.

The first question is whether renal replacement therapy should be included in the UHC benefits package. If the response to that question is "no" or "not for now," the country must come to terms with the persistence of catastrophic health expenditure in the population resulting from ESRD.

Should the country decide to include renal replacement therapy the next decision is which types of treatment should be covered. Pre-emptive kidney transplantation has been shown to provide the best value for investment in many settings. ${ }^{2}$ However, universal access requires availability of sufficient kidney donors in the country and the capacity for providing transplantation and subsequent care. If these two conditions are not met, as was the case in Indonesia, the Philippines, and Thailand, the country has to decide whether to adopt peritoneal dialysis or haemodialysis as the first line of treatment and how this will be implemented.

If the country decides to opt for peritoneal dialysis, it will have to consider patient and provider acceptability as well as the need for a support system in the community since the treatment is largely carried out by patients at home.

If the country opts for haemodialysis first or through a free choice policy, then it has to decide between centre or home based treatment. For in-centre haemodialysis, the country needs to ensure there is sufficient infrastructure available, including haemodialysis machines and accessibility to haemodialysis centres for patients, and a mechanism to ensure adequate treatment is affordable to avoid suboptimal dialysis. The most advanced option is home based treatment, but this requires investment in haemodialysis machines for each patient as well as training of patients and care givers.

None of these options are cheap. Kidney transplantation requires large, upfront investment, even though it is the cheapest and most definitive treatment option in the long term. Peritoneal dialysis is the second cheapest and relatively more cost effective option, with direct medical costs being about $70-80 \%$ of those for in-centre haemodialysis. ${ }^{3}$ Home based haemodialysis is the most expensive treatment option. When a pre-emptive kidney transplantation policy is not viable, offering peritoneal dialysis as the first treatment is the most feasible and scalable option, particularly in low and middle income countries, because it has lower infrastructural requirements. The benefits package should also include effective preventive measures, such as controlling diabetes and hypertension, and workforce training to ensure sustainable management of these high cost treatments. $^{25}$

The experiences of Indonesia, the Philippines, and Thailand suggest that universal renal replacement therapy is a hard but necessary choice for countries to make on their journey towards UHC. Indeed, UHC policies in countries will be judged by how they respond to the needs of patients with ESRD, using it as a barometer for a society's willingness to pay for its healthcare. ${ }^{5}$ A systematic approach to decision making on treating ERSD and other expensive conditions will help ensure that countries make best use of their resources.

The Health Intervention and Technology Assessment Program (HITAP) is funded by the Thailand Research Fund (TRF) under a grant for Senior Research Scholar (RTA5980011). HITAP's International Unit is supported by the International Decision Support Initiative (iDSI) to provide technical assistance on health intervention and technology assessment to governments in low and middle income countries. iDS is funded by the Bill and Melinda Gates Foundation [OPP1134345], the UK's Department for International Development, and the Rockefeller Foundation. The findings, interpretations, and conclusions expressed in this article do not necessarily reflect the views of the funding agencies.

Contributors and sources: All authors work on health technology assessment (HTA) and health systems and policy research. YT is the founder of and senior researcher at the Health Intervention and Technology Assessment Program (HITAP) in the Ministry of Public Health, Thailand, and is a globally recognised leader in the field of HTA; he has led HITAP in supporting the development of HTA in the South-east Asia Region as part of the International Decision Support Initiative (iDSI). SD is manager of HITAP's International Unit and has conducted health systems research in the South-east Asia region. LCK has worked on studies conducted by the HTA Committee in Indonesia. DB was the lead of the HTA Unit in the Department of Health in the Philippines; WI is the director of the Centre for Excellence in Economic Analysis Research (CLEAR) at St Michael's Hospital, University of Toronto and is a senior researcher at HITAP. YT conceived of the article. YT and SD wrote the first draft of the article with inputs from LCK and DB on Indonesia and the Philippines, respectively. LCK, DB, and WI reviewed and provided comments on the draft. YT and SD finalized the article. YT is the guarantor of the article.

Competing interests: We have read and understood BMJ policy on declaration of interests and declare that YT, LCK, and DB conducted economic evaluations of renal dialysis policies in Thailand, Indonesia, and the Philippines, respectively. In Thailand and Indonesia, the studies were used to inform policies or strategies on renal dialysis. YT supervised the studies conducted in Indonesia and the Philippines.

Provenance and peer review: Commissioned; externally peer reviewed. 
This article is part of a series commissioned by The $B M J$. Open access fees are paid for by the Bill and Melinda Gates Foundation, which had no role in the decision to publish.

Yot Teerawattananon, senior researcher ${ }^{1,2}$

Saudamini Vishwanath Dabak, technical adviser ${ }^{1}$ Levina Chandra Khoe, lecturer ${ }^{3}$

Diana Beatriz S Bayani, research associate ${ }^{2,4}$

Wanrudee Isaranuwatchai, senior researcher ${ }^{1,5}$

${ }^{1}$ Health Intervention and Technology Assessment Program (HITAP), Ministry of Public Health, Nonthaburi, Thailand

${ }^{2}$ Saw Swee Hock School of Public Health, National University of Singapore, Singapore

${ }^{3}$ Department of Community Medicine, Faculty of Medicine, Universitas Indonesia, Jakarta, Indonesia

${ }^{4}$ Health Technology Assessment Unit, Department of Health, Manila, Republic of the Philippines

${ }^{5}$ St Michael's Hospital, Li Ka Shing Knowledge Institute, Centre for Excellence in Economic Analysis Research (CLEAR), Toronto, Ontario, Canada

Correspondence to: SV Dabak

saudamini.d@hitap.net

\section{(c) (1) OPEN ACCESS}

This is an Open Access article distributed in accordance with the terms of the Creative Commons Attribution (CC BY 4.0) license, which permits others to distribute, remix, adapt and build upon this work, for commercial use, provided the original work is properly cited. See: http://creativecommons.org/licenses/by/4.0/

Check for updates
1 Liyanage T, Ninomiya T, Jha V, et al. Worldwide access to treatment for end-stage kidney disease: a systematic review. Lancet 2015;385:1975-82. doi:10.1016/S0140-6736(14)61601-9

2 Teerawattananon Y, Luz A, Pilasant S, et al. How to meet the demand for good quality renal dialysis as part of universal health coverage in resourcelimited settings? Health Res Policy Syst 2016;14:21 doi:10.1186/s12961-016-0090-7

3 Mushi L, Marschall P, Fleßa S. The cost of dialysis in low and middle-income countries: a systematic review. BMC Health Serv Res 2015;15:506. doi:10.1186/s12913-015-1166-8

4 Teerawattananon Y, Mugford M, Tangcharoensathien V. Economic evaluation of palliative management versus peritoneal dialysis and hemodialysis for end-stage renal disease: evidence for coverage decisions in Thailand. Value Health 2007;10:61-72. doi:10.1111/j.15244733.2006.00145.x

5 Harris DCH, Davies SJ, Finkelstein FO, et al. Working Groups of the International Society of Nephrology's 2nd Global Kidney Health Summit. Increasing access to integrated ESKD care as part of universal health coverage. Kidney Int 2019;95(4S):S1-33. doi:10.1016/j.kint.2018.12.005

6 Korevaar JC, Feith GW, Dekker FW, et al, NECOSAD Study Group. Effect of starting with hemodialysis compared with peritoneal dialysis in patients new on dialysis treatment: a randomized controlled trial. Kidney Int 2003;64:2222-8. doi:10.1046/j.15231755.2003.00321.x

7 Niang A, lyengar A, Luyckx VA. Hemodialysis versus peritoneal dialysis in resourcelimited settings. Curr Opin Nephrol Hypertens 2018;27:463-71. doi:10.1097/ MNH.0000000000000455

8 Andersen EL. Editor's letter: region on the rise. International Monetary Fund, 2018.

9 World Bank. World development indicators. World Bank, 2017.
10 Tantivess S, Werayingyong P, Chuengsaman P, Teerawattananon Y. Universal coverage of renal dialysis in Thailand: promise, progress, and prospects. BM/ 2013;346:f462. doi:10.1136/bmj.f462

11 Chuengsaman P, Kasemsup V. Peritoneal dialysis first policy: Thailand's response to the challenge of meeting the needs of patients with end-stage renal Disease. Semin Nephrol 2017;37:287-95 doi:10.1016/j.semnephrol.2017.02.008

12 Minister of Health. Keynote speech: Indonesian health system and access to high cost technologies in Indonesia. HTAi Asia Policy Forum in Jakarta, 29 October 2018.

13 Bayani DB, Almirol BJ, Uy GD, et al. Economic evaluation of policy options for renal replacement coverage in the Philippines. National Health Research Forum for Action, 17 July 2019. https:// issuu.com/jakekho/docs/nhrfa17_eprogram

14 Prodjosudjadi W, Suhardjono A. End-stage renal disease in Indonesia: treatment development. Ethn Dis 2009;19(Suppl 1):S1-33, 6.

15 Philippine Renal Disease Registry. Annual report 2016. PRDR, 2016.

16 Thailand National Health Security Office. Annual report 2017. https://www.nhso.go.th/eng/FrontEnd/ page-contentdetail.aspx?CatID=MTAyMw==

17 BPJS Kesehtan. Claims data, 2014.

18 Philippine Health Insurance Corporation (PhilHealth). Claims database 2017.

19 Glassman A, Forman R. Setting universal health coverage priorities: India and dialysis. Center for Global Development, 2016.

20 History of the National Kidney Foundation of Samoa. http://nkfsamoa.org.ws/about/.

21 Essue BM, Jha V, John O, Knight J, Jan S. Universal health coverage and chronic kidney disease in India. Bull World Health Organ 2018;96:442. doi:10.2471/BLT.18.208207

Cite this as: $B M / 2020 ; 368: m 82$

http://dx.doi.org/10.1136/bmj.m82 